\title{
Análise de diferenças de desempenho entre empresas participantes e não participantes do Índice de Sustentabilidade Empresarial da BM\&FBOVESPA
}

\author{
Analysis of differences on performance of companies \\ participating and non-participating of the corporate \\ sustainability index of BM\&FBOVESPA
}

\section{Lívia Arruda Castro' ${ }^{1}$}

\section{Resumo}

Este estudo teve como objetivo principal avaliar o desempenho financeiro de empresas participantes do Índice de Sustentabilidade Empresarial (ISE) da BM\&FBovespa, que reconhecidamente incorporam princípios de sustentabilidade em comparação às empresas não participantes, exceto instituições financeiras. Assim, reuniram-se 28 empresas participantes e 28 empresas não participantes do ISE, para as quais foram coletadas nas Demonstrações Financeiras Padronizadas, na data base 31 de dezembro de 2013, dados financeiros para o cálculo dos índices de estrutura de capital, gestão do capital de giro, liquidez, rentabilidade sobre o investimento, margem de lucratividade e valor de mercado. Foram realizados testes estatísticos de diferenças de médias de Wilcoxon, com nível de confiança 95\%, que avalia se existem diferenças significantes entre os indicadores financeiros das empresas participantes do ISE em relação àquelas não participantes. Como regra geral, os testes revelaram não haver diferenças significantes entre os dois grupos. No entanto, quando a análise é realizada por setor econômico, revela diferenças significantes no setor econômico Materiais Básicos, no índice Margem EBITDA, no setor econômico Utilidade Pública, no índice Cobertura das Despesas Financeiras, quando as empresas participantes do ISE revelaram desempenho significantemente superior às empresas não participantes.

Palavras-chave: Desempenho Financeiro. Sustentatibilidade. Índice de Sustentabilidade Empresarial (ISE).

1 Mestre em Administração e Controladoria pela Universidade Federal do Ceará. Afiliação: FANOR - Faculdade Nordeste. Brasil. Lattes: http://lattes.cnpq.br/2347971516255777 Email: livia.academico@gmail.com 


\section{Abstract}

This study aimed to evaluate the financial performance of companies which participate in the Corporate Sustainability Index (ISE) of BM\&FBovespa, admittedly known for incorporating social and environmental responsibility principles, compared to nonparticipating companies, excluding financial institutions. Thus, we gathered 28 companies participating in the ISE and 28 companies nonparticipating and collected in their Financial Statements as of December 31, 2013 financial data for the calculation of capital structure ratios, management working capital, liquidity, return on investment, profitability margin and market value. We performed statistical tests of differences of means of Wilcoxon, with 95\% confidence level, in order to compare whether there are significant differences between financial indexes of participants of ISE companies and nonparticipants. As a general rule, the tests revealed no significant differences between the two groups. On the other hand, when performing the same analysis by economic sector, it was revealed significant differences in EBITDA margin of the Basic Materials sector, and also in the Financial Expenses Coverage of the Public Utility sector, meaning that companies participating in the ISE showed performance significantly higher than the companies not participating in the ISE.

Keywords: Financial Performance. Social Responsibility.Corporate Sustainability Index (ISE).

\section{Introdução}

As empresas enfrentam cada vez mais novos desafios em razão de exigências dos consumidores e de regras comerciais para o cumprimento de normas éticas, trabalhistas e socioambientais em toda a cadeia produtiva. Nesse contexto, a obtenção de reputação socioambiental demonstra transparência, confiabilidade e sustentabilidade, correspondendo a um relevante diferencial diante da concorrência. O reconhecimento da sustentabilidade transmite características relacionadas com fatores ambientais e sociais politicamente corretos, baseando-se na expectativa de que empresas sustentáveis são mais bem avaliadas pelas partes interessadas, e, portanto, poderão vir a ser mais rentáveis do que outras empresas de seu setor em longo prazo. Esse aspecto pode ser contextualizado com a tendência mundial de investidores procurarem empresas socialmente responsáveis, sustentáveis e rentáveis para aplicar seus recursos. Acredita-se que 
investimentos "sustentáveis" geram valor para o acionista em longo prazo, pois estão mais preparadas para enfrentar riscos econômicos, sociais e ambientais. Essa demanda veio se fortalecendo ao longo do tempo e hoje é amplamente atendida por vários instrumentos financeiros no mercado internacional.

A criação de indicadores socioambientais, como o Índice de Sustentabilidade Empresarial (ISE), em 2005, pela BM\&FBovespa, e o Índice Dow Jones de Sustentabilidade, instituído em 1999, pela Bolsa de Valores de Nova lorque, com o intuito de "destacar as empresas que procuram aliar desenvolvimento com eco-eficiência e responsabilidade social" (MAY; LUSTOSA; VINHA, 2003, p. 189), é um ato que começa a incorporar os riscos sociais e ambientais no mercado de capitais. Além dos indicadores citados, existem outros índices capazes de avaliar o nível de sustentabilidade das organizações para acompanhar e controlar as práticas e estratégias empresariais para obter competitividade e rentabilidade. Entre os principais índices globais, estão: FTSE4good Index Series, Socially Responsible Investing (SRI/JSE), Environmental Sustentability Index (ESI) e Indicadores de desenvolvimento sustentável (IDS-IBGE).

O ISE tem por objetivo refletir o retorno de uma carteira composta por ações de empresas com reconhecido comprometimento com a sustentabilidade empresarial, e também atuar como promotor das boas práticas no meio empresarial brasileiro. Este índice é composto por empresas que se destacam por sua sustentabilidade em longo prazo, correspondendo a um referencial do desempenho das empresas e sendo percebido com credibilidade pelo mercado, além de estimular boas práticas no mercado. As empresas componentes da carteira teórica do ISE são escolhidas com base em um questionário encaminhado anualmente para as 200 empresas com ações mais líquidas da BM\&FBovespa. A seleção das empresas é feita com base na melhor classificação, considerando critérios ambientais, sociais e financeiros, critérios gerais da empresa, critérios de natureza do produto e critérios de governança corporativa, avaliados pela BM\&FBovespa. 
Arevisão das empresas participantes do ISE é realizada anualmente pela BM\&FBovespa, tendo o número de empresas participantes variado entre 28 e 37 empresas desde sua criação, em 2005. Assim, diante de empresas que reconhecidamente incorporam princípios de sustentabilidade, instiga-se a pesquisa sobre o desempenho dessas empresas para compará-lo ao de outras empresas. Acredita-se que esta pesquisa possa contribuir, considerando-se a falta de consenso nos trabalhos que estudam as empresas brasileiras participantes do ISE, para o entendimento da diferença no desempenho financeiro de empresas que adotam práticas de sustentabilidade.

Nesse sentido, formulou-se a seguinte questão de pesquisa: Quais as divergências no desempenho financeiro das empresas participantes do ISE e das empresas que não participam do ISE? Este estudo tem como objetivo principal avaliar o desempenho financeiro de empresas participantes do Índice de Sustentabilidade Empresarial (ISE) da BM\&FBovespa, que reconhecidamente incorporam princípios de sustentabilidade, em comparação às empresas não participantes, exceto instituições financeiras. Para viabilizar o alcance do objetivo geral, foram definidos os seguintes objetivos específicos: (1) mensurar indicadores financeiros quantitativos de empresas participantes e não participantes do ISE; (2) comparar os indicadores financeiros das empresas participantes e das empresas não participantes do ISE; (3) analisar as divergências no desempenho financeiro de empresas participantes e não participantes do ISE por setor de atividade econômica.

Embora exista uma premissa teórica de que empresas que adotam ações de sustentabilidade tenham despertado maior atenção de investidores, essas ações repercutem em custos adicionais para o ganho de imagem da empresa, os quais podem reduzir o lucro atual dos acionistas, pois o custo dessas ações é registrado no presente, enquanto que o retorno dessas ações é percebido em longo prazo.

Assim, este estudo se justifica pela crença de que investidores seriam atraídos a aplicar em empresas sustentáveis por elas criarem valor para os acionistas em longo prazo ao aproveitarem oportunidades 
e gerirem riscos decorrentes da evolução econômica, ambiental e social (KNOEPFEL, 2001). Por ter sido criado recentemente, em novembro de 2005, a literatura não apresenta consenso sobre esta discussão (MACEDO et al., 2007; REZENDE; NUNES; PORTELA, 2008; VITAL et al., 2009; MACHADO; MACHADO; CORRAR, 2009; NUNES et al., 2010; GOMES; TORQUATO, 2011; TODESCHINI; MELLO, 2011; TEIXEIRA; NOSSA; FUNCHAL, 2011; MACEDO; CORRAR; SIQUEIRA, 2012; MAZZIONI et al., 2013; BARAKAT et al., 2016).

Inúmeros estudos já investigaram a relação entre sustentabilidade e performance financeira, mas os resultados são conflitantes, impedindo um consenso a respeito do tema. Acredita-se que este estudo, sob o pressuposto de que investidores perceberiam as atitudes sustentáveis dessas empresas como diferenciais competitivos, possa contribuir com esta discussão ao verificar se o ISE apresenta um retorno superior.

\section{Referencial teórico}

\subsection{Sustentabilidade empresarial}

Barbieri e Cajazeira (2009) definem empresa sustentável como aquela que incorpora os conceitos e objetivos do desenvolvimento sustentável em suas políticas e práticas de um modo consistente. Para se apresentar sustentável, a empresa deve, além de atender as necessidades dos stakeholders, ainda proteger, sustentar e aumentar os recursos humanos e naturais necessários no futuro. Para Strong (1993), a empresa sustentável deve atender simultaneamente aos critérios de equidade social, prudência ecológica e eficiência econômica. Marrewijk (2003) propôs um modelo de responsabilidade social e sustentabilidade com dimensões econômica, social e ambiental, simultaneamente, inseridas no contexto da responsabilidade organizacional, o qual está inserido em um contexto ainda maior de sustentabilidade.

Resgata-se que é a convergência entre diferentes modelos de sustentabilidade organizacional que faz surgir o conceito de empresa sustentável. Ressalta-se também o atendimento às expectativas sociais 
dos trabalhadores, marcadamente no campo da saúde e da segurança, assim como a gestão ambiental empresarial como evolução do simples atendimento às normas legais.

Atualmente, a sustentabilidade empresarial consiste em uma vantagem competitiva no hoje e em longo prazo, uma vez que busca satisfazer as necessidades empresariais presentes sem comprometer as necessidades das gerações futuras, abrangendo, portanto, variáveis econômicas, sociais e ambientais.

\subsection{Revisão de trabalhos que estudaram o ISE}

Macedo et al.(2007) analisaram o desempenho de empresas socialmente responsáveis através de indicadores financeiros de liquidez, endividamento e lucratividade, referentes ao ano de 2005. Os autores selecionaram 29 empresas participantes do ISE em 2006 e outras pertencentes aos mesmos setores, listadas no Guia das 500 maiores e melhores empresas, publicado pela Revista Exame em 2006, para a análise de seus índices de liquidez, endividamento e lucratividade. Os resultados mostraram que, apesar de inicialmente se imaginar que existissem diferenças entre empresas socialmente responsáveis e outras empresas sem esta característica, não se observaram diferenças significantes no ano de 2006 entre os dois grupos de empresas.

Rezende, Nunes e Portela (2008) investigaram, nos dezesseis meses do período compreendido entre dezembro de 2005 e março de 2007, se o retorno do índice de sustentabilidade empresarial é semelhante aos índices de ações convencionais da BM\&Fbovespa. Os autores utilizaram testes estatísticos para comparar o retorno médio do ISE com o retorno médio do Índice Bovespa (Ibovespa), do Índice Brasil (IBrx) e do Índice de Ações com Governança Corporativa Diferenciada (IGC). Os achados confirmaram a hipótese de que, apesar do ISE possuir uma carteira teórica diferenciada, seu retorno médio não possui diferenças significantes em relação aos demais índices de ações, indicando que, mesmo selecionando empresas considerando o conceito 
de sustentabilidade, o ISE não possui melhor retorno que outros índices de ações.

Gallon e Ensslin (2008) investigaram a evidenciação dos elementos que são pilares do ISE (empregados, fornecedores, comunidade, governança corporativa e meio ambiente) nos relatórios da administração das 34 empresas que, de dezembro de 2006 a novembro de 2007, compunham a carteira teórica do ISE, no período de 2000 a 2006, por meio da técnica da análise de conteúdo. Os resultados desse estudo revelaram que os elementos empregados e fornecedores foram os mais evidenciados, seguidos do elemento meio ambiente, e o elemento governança corporativa foi o que teve menor evidenciação. Além disso, os resultados constaram que $62,96 \%$ das empresas analisadas classificaram-se com evidenciação moderada, já 25,93\% das empresas classificaram-se com evidenciação baixa, e apenas $11,11 \%$ das empresas classificaram-se com evidenciação elevada, o que mostra que as empresas ainda têm um longo caminho a trilhar no sentido da transparência e qualidade da divulgação de suas práticas sustentáveis.

Vital et al. (2009) compararam o desempenho de indicadores financeiros de 20 empresas brasileiras listadas no Guia das 500 maiores e melhores da Revista Exame, algumas que faziam parte do ISE e outras que não faziam. Os autores analisaram os indicadores de Vendas (em valor e crescimento), Lucro líquido, Rentabilidade, Capital circulante líquido, Liquidez geral, Endividamento geral, Endividamento de longo prazo, EBITDA e indicadores de exportação, referentes ao ano de 2008, com base na média aritmética dos números absolutos. Os resultados revelaram que as empresas que compõem a carteira teórica do ISE apresentaram melhor desempenho apenas nos indicadores referentes às vendas e às exportações. Logo, as empresas que não faziam parte do ISE foram melhores quanto ao crescimento, ao lucro, à lucratividade, à rentabilidade, ao endividamento e ao EBITDA.

Machado, Machado e Corrar (2009) investigaram se a rentabilidade média do ISE é estatisticamente igual à rentabilidade dos demais índices da BOVESPA, no período de dezembro de 2005 a novembro 2007, e 
concluíram não haver diferença significativa entre o ISE e os demais índices da BOVESPA. O resultado apresentado não pode levar à conclusão de que investimentos socialmente responsáveis apresentam o mesmo retorno de investimentos que não adotam postura idêntica, mas que o retorno médio dos índices é semelhante, uma vez que um número relevante de empresas compõe simultaneamente mais de um índice.

Nunes et al. (2010) verificaram a relação do tamanho, setor de atividade, concentração acionária e localização à adesão das empresas ao ISE. Os autores analisaram as empresas que possuem as 119 ações mais líquidas listadas na BM\&FBovespa, entre participantes e não participantes do ISE. Foi aplicado o modelo Logit de regressão linear múltipla para avaliar a contribuição de cada variável explicativa para estimar a variável dependente dummy (adesão ou não ao ISE). As variáveis independentes estudadas foram tamanho da empresa, setor econômico, concentração acionária e localização. Os autores concluíram que há indícios de que o tamanho das empresas e o setor econômico sejam fatores determinantes para a adesão da empresa ao ISE. Também identificaram que as variáveis localização e concentração acionária não apresentaram indícios de influência na participação das empresas no ISE.

Gomes e Torquato (2011) investigaram se o retorno médio das empresas participantes do ISE é semelhante a outros índices de ações da BM\&Fbovespa. Foram realizados testes estatísticos que comparam o retorno médio do ISE com o retorno médio do Índice Bovespa (IBOV) e do Índice de Ações com Governança Corporativa Diferenciada (IGC). Os resultados revelaram que, apesar do ISE possuir uma carteira teórica diferenciada, o seu retorno não possui diferenças significantes aos demais índices de ações convencionais.

Todeschini e Mello (2011) verificaram se empresas de alguns setores econômicos participantes do ISE revelavam indicadores de rentabilidade superiores àqueles das empresas não participantes no período de 2006 a 2009, e identificaram que apenas nos setores de 
Consumo não cíclico/Saúde e Financeiros e outros/Intermediários financeiros as empresas participantes do ISE mostraram-se superiores. Segundo os autores, as ações de RSE adotadas pelas empresas vêm se disseminando e despertando a atenção de empresas e investidores, o que também levou os mercados financeiros a buscarem índices capazes de refletir o desempenho das empresas nessa área de atuação. No entanto, o retorno financeiro dessas ações não é matéria de fácil mensuração, pois os investimentos em ações de responsabilidade social e ambiental podem acarretar custos adicionais, mas, ao mesmo tempo, podem possibilitar a melhoria no desempenho financeiro por meio dos ganhos para a imagem da empresa e da redução de eventuais passivos trabalhistas ambientais.

Teixeira, Nossa e Funchal (2011) investigaram se a forma de financiamento das empresas é afetada pela sua participação ISE. Foi utilizada uma amostra de 378 empresas, dividida em 94 que participavam do ISE e 284 que não participavam. Considerando que o ISE foi criado em dezembro de 2005, o período estudado compreendeu os anos de 2003 a 2008, no intuito de realizar uma comparação entre os três anos antes da primeira carteira (2003-2005) e os três anos com a carteira ISE (2006-2008). Os resultados revelaram que as empresas participantes tiveram uma relação negativa com o endividamento e o risco ao serem comparadas com aquelas que não participavam, destacando a relevância dos índices de sustentabilidade como um canal de informação crível do comprometimento da empresa com a sustentabilidade.

Macedo, Corrar e Siqueira (2012) compararam o desempenho financeiro de empresas do setor de distribuição de energia elétrica no Brasil, incluindo as socioambientalmente responsáveis e outras sem essa característica, no período de 2005 a 2007. Para separar os dois grupos, utilizou-se o critério de estar listada no ISE em, pelo menos, três anos completos, de 2006 a 2008. Foi aplicada a análise envoltória de dados aos índices de Lucratividade, Margem de lucro, Giro do ativo, Liquidez, Endividamento e Imobilização das empresas no período de 2005 a 2007. Os resultados revelaram que as empresas participantes do ISE apresentaram desempenho financeiro estatisticamente superior, 
podendo-se concluir pela superioridade de desempenho das empresas socioambientalmente responsáveis no período estudado.

Pletsch, Silva e Hein (2015) analisaram a relação entre a sustentabilidade e o desempenho financeiro das empresas listadas no ISE, no período compreendido entre 2008 e 2012. Foram coletadas informações de desempenho econômico financeiro, benefícios internos e benefícios sociais externos por meio de relatórios de sustentabilidade e do balanço social das empresas. Foram aplicados testes estatísticos para análise de correlação canônica, que verificou as variáveis do estudo de duas formas: relação entre as variáveis de Benefícios sociais internos e Desempenho econômico financeiro, e entre as variáveis de Benefícios sociais externos e o Desempenho econômico financeiro. Os resultados mostraram que o Desempenho econômico financeiro influencia, tanto nos Benefícios sociais internos quanto nos Benefícios sociais externos, concluindo-se que, quanto maior for o Desempenho econômico financeiro das empresas, maiores serão os investimentos destinados ao público interno das organizações, e, em seguida, os investimentos em Benefícios sociais externos, destinados à sociedade.

Mazzioni et al. (2013) compararam o desempenho na geração e distribuição do valor adicionado de empresas participantes do ISE e das demais empresas listadas na BM\&FBovespa. Foram realizados testes estatísticos em onze indicadores relacionados ao valor adicionado em uma amostra composta por: 143 empresas em 2009, 182 empresas em 2010 e 185 empresas em 2011. Os achados mostraram que as empresas pertencentes ao ISE apresentaram desempenho estatisticamente superior no montante médio de valor adicionado gerado pelos três períodos investigados, o que permite concluir que as empresas não participantes do ISE remuneram expressivamente mais o capital de terceiros, enquanto que as empresas participantes apresentam pagamentos superiores ao capital próprio.

Barakat et al. (2016) investigaram se empresas listadas no ISE apresentam retornos financeiros superiores aos das demais empresas da BM\&FBovespa. A amostra utilizada foi de 120 meses, de novembro 
de 2005 (quando o índice foi criado) até novembro de 2015. Para análise dos dados, foi realizada uma comparação do comportamento das ações do agregado de empresas que compõem a carteira do ISE em relação às demais ações do mercado. O principal diferencial do presente estudo, em relação a outros realizados com dados do ISE, é que a comparação não foi feita diretamente com o Ibovespa, visto que o ele contém também as ações do ISE. As empresas do ISE foram extraídas da carteira do Ibovespa e o índice das empresas restantes foi reconstruído seguindo a mesma metodologia do Ibovespa e, dessa maneira, o desempenho do ISE foi comparado com o índice Ibovespa, mas excluídas as participantes do ISE. Os resultados encontrados mostraram evidências da superioridade da carteira do ISE contra as demais empresas no período observado.

\section{Metodologia}

Este estudo empírico tem caráter hipotético indutivo, buscando inferências a partir de dados de amostra de índices calculados por meio de demonstrações contábeis de empresas brasileiras participantes e não participantes do ISE. Essas inferências apóiam-se em resultados estatísticos, explanatórios das evidências empíricas que suportam este estudo. Os procedimentos utilizados nesta pesquisa são classificados como dentro de um enfoque empírico analítico, uma vez que compreendem técnicas de coleta, tratamento e análise de dados quantitativos, com forte preocupação com a relação causal entre as variáveis, e a validação da prova científica é buscada através de testes de graus de significância (MARTINS, 1994).

Este estudo possui abordagem quantitativa, uma vez que foi feito com base em dados estatísticos. Quanto aos objetivos, esta pesquisa classifica-se como descritiva, uma vez que tem como objetivo primordial a descrição das características de determinada população. Neste caso, empresas brasileiras participantes e não participantes do ISE. Também é classificado como documental, devido ao procedimento adotado para a coleta de dados, em que se utilizou dados secundários extraídos dos relatórios anuais de empresas listadas na BM\&FBovespa. 
O ISE foi lançado pela BM\&FBovespa em 2005, tendo o intuito de atender a um segmento de mercado através de um indicador que apontasse as empresas com desempenho financeiro relevante relacionado a ações de sustentabilidade social e ambiental, servindo como indicador para os investidores que procuram empresas com esse perfil para realizar suas aplicações. Para compor sua carteira, o ISE aplica anualmente um questionário voluntário às empresas e avalia seu comprometimento com as questões de sustentabilidade. As respostas das companhias são analisadas por uma ferramenta estatística chamada "análise de clusters", que identifica grupos de empresas com desempenhos similares e aponta o grupo com melhor desempenho geral. As empresas desse grupo irão compor a carteira final do ISE (que terá um número máximo de 40 empresas) após aprovação do Conselho deliberativo do ISE (BM\&FBOVESPA, 2014).

Foram selecionadas para compor a amostra da pesquisa 28 empresas não financeiras participantes do ISE em 31 de março 2014, e 28 empresas atuantes no mesmo setor econômico, porém, não participantes do ISE. Portanto, uma amostra final composta por 56 companhias brasileiras. Para a escolha das empresas não participantes do ISE, elegeram-se prioritariamente aquelas companhias que, além de serem do mesmo setor econômico, também eram do mesmo segmento, conforme classificação da BM\&FBovespa. Caso não houvesse outra empresa classificada no mesmo segmento, ou caso houvesse mais de uma empresa listada no mesmo segmento, eram priorizadas aquelas empresas listadas no Novo Mercado, por possuírem o mais elevado padrão de governança corporativa.

Para não distorcer os resultados, optou-se por excluir as instituições financeiras tendo em vista que as mesmas estão sujeitas a normatização específica do Banco Central, além de não serem aplicáveis alguns indicadores investigados na pesquisa, tais como índices de Liquidez seca e de Gestão de capital de giro. A amostra deste estudo caracteriza-se como não-probabilística, devendo-se ressaltar que os resultados desta pesquisa não podem ser generalizados para a utilização de padrões contábeis brasileiros e internacionais de outras 
empresas. O número de empresas selecionadas por setor, participantes e não participantes do ISE, está relacionado abaixo na tabela 1.

Tabela 1 - $\mathrm{N}^{\circ}$ de empresas participantes e não participantes do ISE

\begin{tabular}{l|c|c}
\hline Setor econômico & $\begin{array}{c}\mathbf{N}^{\circ} \text { de empresas } \\
\text { participantes do ISE }\end{array}$ & $\begin{array}{c}\mathbf{N}^{\circ} \text { de empresas não } \\
\text { participantes do ISE }\end{array}$ \\
\hline Bens industriais & 2 & 2 \\
\hline Consumo não básico & 1 & 1 \\
\hline Consumo cíclico & 1 & 1 \\
\hline Consumo não cíclico & 1 & 1 \\
\hline $\begin{array}{l}\text { Construção e } \\
\text { transporte }\end{array}$ & 1 & 7 \\
\hline Materiais básicos & 7 & 2 \\
\hline Telecomunicações & 2 & 13 \\
\hline Utilidade pública & 13 & 28 \\
\hline TOTAL & 28 & 1 \\
\hline
\end{tabular}

Fonte: Elaborado pelo autor.

No quadro 1, estão relacionadas as empresas participantes e não participantes do ISE que foram selecionadas para o estudo, considerando-se a data base de 31 de março de 2014.

Quadro 1 - Amostra de empresas selecionadas para o estudo

\begin{tabular}{|l|l|l|}
\hline \multirow{2}{*}{ Setor } & Empresas participantes do ISE & $\begin{array}{l}\text { Empresas não participantes } \\
\text { do ISE }\end{array}$ \\
\hline \multirow{2}{*}{ Bens industriais } & Indústrias Romi S.A. & $\begin{array}{l}\text { Nordon Indústrias Metalúrgicas } \\
\text { S.A. }\end{array}$ \\
\cline { 2 - 3 } & Embraer S. A. & Autometal S.A. \\
\hline $\begin{array}{l}\text { Consumo não } \\
\text { básico }\end{array}$ & BRF - Brasil Foods S.A. & JBS S.A. \\
\hline $\begin{array}{l}\text { Consumo não } \\
\text { cíclico }\end{array}$ & Natura Cosméticos S.A. & Avon Products Inc. \\
\hline $\begin{array}{l}\text { Construção e } \\
\text { transporte }\end{array}$ & $\begin{array}{l}\text { Even Construtora e Incorporadora } \\
\text { S.A. }\end{array}$ & Cyrela Brazil Realty S.A. \\
\hline Consumo cíclico & $\begin{array}{l}\text { Anhanguera Educacional } \\
\text { Participações S.A. }\end{array}$ & Estácio Participações S.A. \\
\hline
\end{tabular}




\begin{tabular}{|c|c|c|}
\hline \multirow{7}{*}{ Materiais básicos } & Duratex S.A. & Eucatex S.A. \\
\hline & Fibria Celulose S.A. & Klabin S/A \\
\hline & Suzano Papel e Celulose S.A. & $\begin{array}{l}\text { Companhia Melhoramentos de } \\
\text { São Paulo }\end{array}$ \\
\hline & Vale S. A. & $\begin{array}{l}\text { MMX Mineração e Metálicos } \\
\text { S.A. }\end{array}$ \\
\hline & Braskem S.A. & Unipar Participações S.A. \\
\hline & Gerdau S.A. & $\begin{array}{l}\text { Companhia de Ferro Ligas da } \\
\text { Bahia }\end{array}$ \\
\hline & Metalúrgica Gerdau S.A. & $\begin{array}{l}\text { Usinas Siderúrgicas de Minas } \\
\text { Gerais S.A. }\end{array}$ \\
\hline \multirow{2}{*}{ Telecomunicação } & Telemar Norte Leste S. A. & Brasil Telecom S.A. \\
\hline & Tim Participações S.A. & Vivo Participações S.A. \\
\hline \multirow{13}{*}{ Utilidade pública } & $\begin{array}{l}\text { Companhia de Saneamento de } \\
\text { Minas Gerais }\end{array}$ & $\begin{array}{l}\text { Companhia de Saneamento do } \\
\text { Paraná }\end{array}$ \\
\hline & $\begin{array}{l}\text { Companhia de Saneamento Básico } \\
\text { do Estado de São Paulo }\end{array}$ & Sanesalto Saneamento S.A. \\
\hline & AES Tietê S.A. & Ampla Energia e Serviços S.A. \\
\hline & $\begin{array}{l}\text { Companhia Energética de Minas } \\
\text { Gerais }\end{array}$ & $\begin{array}{l}\text { Companhia Energética de } \\
\text { Pernambuco }\end{array}$ \\
\hline & Companhia Energética de São Paulo & $\begin{array}{l}\text { Companhia Energética do } \\
\text { Maranhão }\end{array}$ \\
\hline & Companhia Energética do Ceará & $\begin{array}{l}\text { Companhia de Eletricidade do } \\
\text { Estado da Bahia }\end{array}$ \\
\hline & Companhia Paranaense de Energia & $\begin{array}{l}\text { Companhia Energética do Rio } \\
\text { Grande do Norte }\end{array}$ \\
\hline & CPFL Energia S.A. & Equatorial Energia S.A. \\
\hline & Centrais Elétricas Brasileiras S.A. & $\begin{array}{l}\text { Espírito Santo Centrais } \\
\text { Elétricas S.A. }\end{array}$ \\
\hline & $\begin{array}{l}\text { Eletropaulo Metropolitana } \\
\text { Eletricidade de São Paulo S.A. }\end{array}$ & Rede Energia S.A. \\
\hline & EDP - Energias do Brasil S.A. & $\begin{array}{l}\text { Centrais Elétricas de Santa } \\
\text { Catarina S.A. }\end{array}$ \\
\hline & Light S.A. & $\begin{array}{l}\text { Centrais Elétricas } \\
\text { Matogrossenses S.A. }\end{array}$ \\
\hline & Tractebel Energia S.A. & Energética Barra Grande S.A. \\
\hline
\end{tabular}

Fonte: BM\&FBOVESPA (2014) 
Para cada uma das empresas acima, foram coletadas, na data base 31 de dezembro de 2013, as informações financeiras necessárias para o cálculo dos índices relacionados no quadro 2, a seguir:

Quadro 2 - Índices selecionados para o estudo

\begin{tabular}{|c|c|c|}
\hline Tipo do índice & Nome do índice & Fórmula do índice \\
\hline \multirow{3}{*}{$\begin{array}{l}\text { 1. Estrutura de } \\
\text { capital }\end{array}$} & $\begin{array}{l}\text { 1.1. Composição do } \\
\text { Endividamento }\end{array}$ & $\begin{array}{l}\text { Passivo circulante/(Passivo } \\
\text { circulante + Passivo não } \\
\text { circulante) }\end{array}$ \\
\hline & $\begin{array}{l}\text { 1.2. Participação de capital } \\
\text { de terceiros }\end{array}$ & $\begin{array}{l}\text { (Passivo Circulante + não } \\
\text { circulante)/ Patrimônio } \\
\text { líquido }\end{array}$ \\
\hline & $\begin{array}{l}\text { 1.3. Imobilização do } \\
\text { patrimônio líquido }\end{array}$ & $\begin{array}{l}\text { (Investimentos + Imobilizado } \\
+ \text { Intangível) / Patrimônio } \\
\text { líquido }\end{array}$ \\
\hline \multirow{2}{*}{$\begin{array}{l}\text { 2. Gestão do } \\
\text { capital de giro }\end{array}$} & 2.1. Margem EBITDA & EBITDA / Receita líquida \\
\hline & $\begin{array}{l}\text { 2.2. Cobertura de despesas } \\
\text { financeiras }\end{array}$ & $\begin{array}{l}\text { EBITDA / Despesas } \\
\text { financeiras }\end{array}$ \\
\hline \multirow{2}{*}{ 3. Liquidez } & 3.1. Liquidez Corrente & $\begin{array}{l}\text { Ativo circulante / Passivo } \\
\text { circulante }\end{array}$ \\
\hline & 3.2. Liquidez seca & $\begin{array}{l}\text { (Ativo circulante - Estoques) } \\
\text { / Passivo circulante }\end{array}$ \\
\hline \multirow{3}{*}{$\begin{array}{l}\text { 4. Rentabilidade } \\
\text { sobre o } \\
\text { investimento }\end{array}$} & 4.1. Rentabilidade do Ativo & Lucro líquido / Ativo Total \\
\hline & $\begin{array}{l}\text { 4.2. Rentabilidade do } \\
\text { Patrimônio líquido }\end{array}$ & $\begin{array}{l}\text { Lucro líquido / Patrimônio } \\
\text { líquido }\end{array}$ \\
\hline & 5.2. Preço/Lucro & $\begin{array}{l}\text { Valor de mercado da ação / } \\
\text { Lucro por ação }\end{array}$ \\
\hline \multirow{3}{*}{$\begin{array}{l}\text { 5. Margem de } \\
\text { lucratividade }\end{array}$} & 5.1. Margem bruta & Lucro bruto /Receita líquida \\
\hline & 5.2. Margem operacional & $\begin{array}{l}\text { Lucro operacional / Receita } \\
\text { líquida }\end{array}$ \\
\hline & 5.3. Margem líquida & $\begin{array}{l}\text { Lucro líquido / Receita } \\
\text { líquida }\end{array}$ \\
\hline \multirow{2}{*}{$\begin{array}{l}\text { 6. Valor de } \\
\text { mercado }\end{array}$} & $\begin{array}{l}\text { 6.1. Preço/Valor patrimonial } \\
\text { da ação }\end{array}$ & \begin{tabular}{|l|} 
Valor de mercado da ação / \\
Patrimônio líquido por ação
\end{tabular} \\
\hline & 6.2. Preço/Lucro & $\begin{array}{l}\text { Valor de mercado da ação / } \\
\text { Lucro por ação }\end{array}$ \\
\hline
\end{tabular}

Fonte: Elaborado pelo autor. 
As informações contábeis referentes às empresas selecionados foram coletadas no website da BM\&FBovespa (http://www.bmfbovespa. com.br), na seção "Informações relevantes", subseção "Dados Econômico Financeiros", nos relatórios "Demonstrações Financeiras Anuais Completas", em agosto de 2014. As informações referentes à cotação de mercado das ações das companhias selecionadas foram coletadas na seção "Histórico de Cotações". Para as empresas que não tiveram negociação em 31/12/2013, data base escolhida para análise dos dados da pesquisa, coletou-se a cotação mais recente anterior a essa data. Os dados coletados foram transcritos para planilhas eletrônicas e agrupados conforme a participação ou não no ISE.

Também foram registradas na planilha a razão social da empresa, as moedas de apresentação e as unidades em que os valores foram divulgados. Concluída a tabulação dos dados, calcularam-se os índices descritos no quadro 2, agrupando-os segundo a participação ou não da empresa no ISE. Verificou-se que as empresas Gerdau S.A. e Metalúrgica Gerdau S.A., participantes do ISE, e a não participante Nordon Indústrias Metalúrgicas S.A. não apresentaram atividades operacionais no período da coleta. Desta forma, os índices que possuíam o componente receita líquida não puderam ser calculados para essas companhias, o que determinou sua exclusão da análise dos indicadores margem EBITDA, margem bruta, margem operacional e margem líquida.

Neste estudo, utilizou-se a técnica estatística de diferenças entre médias para duas amostras (empresas participantes e empresas não participantes do ISE) que consiste em examinar se a diferença entre as médias de dois grupos de variáveis é significantemente relevante do ponto de vista estatístico. Os testes estatísticos foram realizados com auxílio do programa Statistical Package for the Social Sciences (SPSS) 18.0 for Windows, um software de análise estatística para uso em pesquisas. Examinou-se se os dados da amostra apresentavam distribuição normal realizando o teste de Kolmogorov-Smirnov. No entanto, os resultados revelaram que os dados da amostra não eram paramétricos. Assim, foram realizados testes para dados não paramétricos de diferenças de 
médias de Wilcoxon para as duas amostras relacionadas. Os testes estatísticos foram realizados com nível de confiança $95 \%$.

\section{Análise dos resultados}

Nesta seção, analisam-se os resultados dos testes estatísticos, os quais foram distribuídos em duas partes. A primeira apresenta os resultados gerais dos indicadores financeiros de companhias participantes e não participantes do ISE, enquanto a segunda discute os resultados por setor econômico.

\subsection{Análise geral dos indicadores financeiros de companhias participantes e não participantes do ISE}

A tabela 2 apresenta os resultados dos testes de diferenças entre médias dos indicadores de companhias participantes e não participantes do ISE. Observa-se que os resultados não relevaram diferenças estatisticamente significantes entre as empresas participantes e não participantes do ISE.

Tabela 2 - Resultado geral dos testes de diferenças entre médias

\begin{tabular}{|c|c|c|c|c|c|c|}
\hline \multirow{3}{*}{ Tipo de Índice } & \multirow{3}{*}{ Índice } & \multirow{3}{*}{$\begin{array}{l}\text { Tipo de } \\
\text { empresa }\end{array}$} & \multirow{3}{*}{$\begin{array}{c}\mathrm{N}^{\circ} \text { de } \\
\text { observações }\end{array}$} & & \multicolumn{2}{|c|}{$\begin{array}{r}\text { Teste de } \\
\text { Wilcoxon }\end{array}$} \\
\hline & & & & \multirow{2}{*}{ Média } & \multirow{2}{*}{ z } & Sig. \\
\hline & & & & & & (P-value) \\
\hline \multirow{6}{*}{$\begin{array}{l}\text { 1. Estrutura } \\
\text { de capital }\end{array}$} & \multirow{2}{*}{$\begin{array}{l}\text { 1.1. Composição } \\
\text { do Endividamento }\end{array}$} & ISE & 28 & 0,33 & \multirow{2}{*}{$-1,12$} & \multirow{2}{*}{0,26} \\
\hline & & Não ISE & 28 & 0,38 & & \\
\hline & \multirow{2}{*}{$\begin{array}{l}\text { 1.2. Participação } \\
\text { de capital de } \\
\text { terceiros }\end{array}$} & ISE & 28 & 1,08 & \multirow{2}{*}{$-1,00$} & \multirow{2}{*}{0,32} \\
\hline & & Não ISE & 28 & 1,01 & & \\
\hline & \multirow{2}{*}{$\begin{array}{l}\text { 1.3. Imobilização } \\
\text { do patrimônio } \\
\text { líquido }\end{array}$} & ISE & 28 & 1,30 & \multirow{2}{*}{$-0,18$} & \multirow{2}{*}{0,86} \\
\hline & & Não ISE & 28 & 1,06 & & \\
\hline
\end{tabular}




\begin{tabular}{|c|c|c|c|c|c|c|}
\hline \multirow{4}{*}{$\begin{array}{l}\text { 2. Gestão do } \\
\text { capital de giro }\end{array}$} & \multirow{2}{*}{$\begin{array}{l}\text { 2.1. Margem } \\
\text { EBITDA }\end{array}$} & ISE & 26 & 0,41 & \multirow{2}{*}{$-1,21$} & \multirow{2}{*}{0,23} \\
\hline & & Não ISE & 27 & 1,52 & & \\
\hline & \multirow{2}{*}{$\begin{array}{l}\text { 2.2. Cobertura } \\
\text { de despesas } \\
\text { financeiras }\end{array}$} & ISE & 28 & 5,64 & \multirow{2}{*}{$-1,66$} & \multirow{2}{*}{0,10} \\
\hline & & Não ISE & 28 & 4,31 & & \\
\hline \multirow{4}{*}{ 3. Liquidez } & \multirow{2}{*}{$\begin{array}{l}\text { 3.1. Liquidez } \\
\text { Corrente }\end{array}$} & ISE & 28 & 1,71 & \multirow{2}{*}{$-0,77$} & \multirow{2}{*}{0,44} \\
\hline & & Não ISE & 28 & 1,46 & & \\
\hline & \multirow{2}{*}{ 3.2. Liquidez seca } & ISE & 28 & 1,56 & \multirow{2}{*}{$-0,93$} & \multirow{2}{*}{0,35} \\
\hline & & Não ISE & 28 & 1,27 & & \\
\hline \multirow{4}{*}{$\begin{array}{l}4 . \\
\text { Rentabilidade } \\
\text { sobre o } \\
\text { investimento }\end{array}$} & \multirow{2}{*}{$\begin{array}{l}\text { 4.1. Rentabilidade } \\
\text { do Ativo }\end{array}$} & ISE & 28 & 0,08 & \multirow{2}{*}{$-1,53$} & \multirow{2}{*}{0,13} \\
\hline & & Não ISE & 28 & 0,05 & & \\
\hline & \multirow{2}{*}{$\begin{array}{l}\text { 4.2. Rentabilidade } \\
\text { do Patrimônio } \\
\text { líquido }\end{array}$} & ISE & 28 & 0,17 & \multirow[b]{2}{*}{$-0,64$} & \multirow[b]{2}{*}{0,52} \\
\hline & & Não ISE & 28 & 0,17 & & \\
\hline \multirow{6}{*}{$\begin{array}{l}\text { 5. Margem de } \\
\text { lucratividade }\end{array}$} & \multirow{2}{*}{$\begin{array}{l}\text { 5.1. Margem } \\
\text { bruta }\end{array}$} & ISE & 26 & 0,39 & \multirow{2}{*}{$-0,22$} & \multirow{2}{*}{0,83} \\
\hline & & Não ISE & 27 & 0,41 & & \\
\hline & \multirow{2}{*}{$\begin{array}{l}\text { 5.2. Margem } \\
\text { operacional }\end{array}$} & ISE & 26 & 0,31 & \multirow{2}{*}{$-0,47$} & \multirow{2}{*}{0,64} \\
\hline & & Não ISE & 27 & 1,45 & & \\
\hline & \multirow{2}{*}{$\begin{array}{l}\text { 5.3. Margem } \\
\text { líquida }\end{array}$} & ISE & 26 & 0,59 & \multirow{2}{*}{$-1,28$} & \multirow{2}{*}{0,20} \\
\hline & & Não ISE & 27 & 1,26 & & \\
\hline \multirow{4}{*}{$\begin{array}{l}\text { 6. Valor de } \\
\text { mercado }\end{array}$} & \multirow{2}{*}{$\begin{array}{l}\text { 6.1. Preço/Valor } \\
\text { patrimonial da } \\
\text { ação }\end{array}$} & ISE & 28 & 2,19 & \multirow{2}{*}{$-0,84$} & \multirow{2}{*}{0,40} \\
\hline & & Não ISE & 28 & 1,49 & & \\
\hline & 62 Precollaro & ISE & 28 & 15,24 & 031 & $072-13$ \\
\hline & 6.2. Preço/Lucro & Não ISE & 28 & 22,89 & $-0,34$ & 0,13 \\
\hline
\end{tabular}

Fonte: Elaborado pelo autor.

No entanto, sem considerar significância estatística para as diferenças observadas, houve diferenças nos indicadores entre os dois grupos de empresas. Os indicadores de estrutura de capital das empresas participantes do ISE revelaram-se superiores apenas no índice composição do endividamento. Já para os índices de participação de capital de terceiros e de Imobilização do patrimônio líquido, as empresas não participantes do ISE que apresentaram o melhor desempenho. Para os índices de gestão do capital de giro, as empresas não participantes do ISE revelaram superioridade apenas no índice margem EBITDA, 
enquanto as empresas consideradas sustentáveis apresentam melhor desempenho no índice cobertura de despesas financeiras. Os índices de liquidez, tanto liquidez corrente quanto liquidez seca, revelaram-se superiores nas empresas participantes do ISE. Na análise dos índices de rentabilidade sobre o investimento, o índice rentabilidade sobre o patrimônio líquido se revelou bem próximo em ambos os grupos de empresas. No entanto, foi superior nas empresas participantes do ISE. Em consonância, o índice rentabilidade sobre o ativo também se mostrou superior nas empresas consideradas sustentáveis. Por outro lado, em relação à margem de lucratividade, as empresas não participantes do ISE apresentaram o melhor desempenho em todos os índices analisados: margem bruta, margem operacional e margem líquida. Os índices de valor de mercado, tanto preço/valor patrimonial da ação quanto preço/ lucro, foram superiores nas empresas participantes do ISE.

\subsection{Análise por setor econômico dos indicadores financeiros de companhias participantes e não participantes do ISE}

Para investigar em maior profundidade as diferenças descobertas, as 28 empresas foram segregadas por setor econômico, conforme a classificação da BM\&FBovespa. Foram realizados novamente testes de diferenças de médias para as companhias participantes de não participantes do ISE, desta vez considerando o setor econômico.

No processamento dos testes estatísticos por setor econômico, os resultados para os setores de Consumo não básico, Consumo cíclico, Consumo não cíclico, e Construção e transporte foram considerados como resultados omissos ("missingvalues"), para os quais existem outras técnicas mais sofisticadas de processamento de dados, as quais não foram utilizadas nessa pesquisa.

Na análise dos índices de Estrutura de capital (tabela 3), não foram observadas diferenças significantes entre os grupos de companhias participantes e não participantes do ISE. 
Tabela 3 - Resultado dos testes de diferenças entre médias de índices de Estrutura de capital

\begin{tabular}{|c|c|c|c|c|c|c|c|c|c|c|c|c|}
\hline \multirow{3}{*}{ Índice } & \multicolumn{4}{|c|}{$\begin{array}{l}\text { 1.1. Composição do } \\
\text { endividamento }\end{array}$} & \multicolumn{4}{|c|}{$\begin{array}{l}\text { 1.2. Participação de capital de } \\
\text { terceiros }\end{array}$} & \multicolumn{4}{|c|}{$\begin{array}{l}\text { 1.3. Imobilização do patrimônio } \\
\text { líquido }\end{array}$} \\
\hline & \multicolumn{2}{|c|}{ Média } & \multirow[b]{2}{*}{ z } & \multirow{2}{*}{$\frac{\text { Sig. }}{\text { (P-value })}$} & \multicolumn{2}{|c|}{ Média } & \multirow[b]{2}{*}{ z } & \multirow{2}{*}{$\begin{array}{l}\text { Sig. } \\
\text { (P-value) }\end{array}$} & \multicolumn{2}{|c|}{ Média } & \multirow[b]{2}{*}{ z } & \multirow{2}{*}{$\frac{\text { Sig. }}{\text { (P-value) }}$} \\
\hline & ISE & $\begin{array}{l}\text { Não } \\
\text { ISE }\end{array}$ & & & ISE & $\begin{array}{l}\text { Não } \\
\text { ISE }\end{array}$ & & & ISE & $\begin{array}{l}\text { Não } \\
\text { ISE }\end{array}$ & & \\
\hline $\begin{array}{l}\text { Bens } \\
\text { industriais }\end{array}$ & 0,41 & 0,59 & $-1,34$ & 0,18 & 1,53 & $\mid-0,31$ & $-1,34$ & 0,18 & 0,77 & 0,49 & $-0,45$ & 0,65 \\
\hline $\begin{array}{l}\text { Materiais } \\
\text { básicos }\end{array}$ & 0,22 & 0,40 & $-1,52$ & 0,13 & 0,84 & 0,89 & $-0,17$ & 0,87 & 1,35 & 1,07 & $-1,52$ & 0,13 \\
\hline $\begin{array}{l}\text { Telecomu } \\
\text { nicação }\end{array}$ & 0,44 & 0,46 & $-0,45$ & 0,66 & 1,57 & 0,76 & $-1,34$ & 0,18 & 1,73 & 0,98 & $-0,45$ & 0,65 \\
\hline $\begin{array}{l}\text { Utilidade } \\
\text { pública }\end{array}$ & 0,32 & 0,31 & $-0,4$ & 0,97 & 1,23 & 1,18 & $-1,29$ & 0,20 & 1,41 & 1,09 & $-0,11$ & 0,92 \\
\hline
\end{tabular}

Fonte: Elaborado pelo autor.

Na análise dos índices de Gestão do capital de giro (tabela 4), foram reveladas diferenças significantes entre os índices das companhias participantes e não participantes do ISE. No setor de Materiais básicos, a margem EBITDA das companhias sustentáveis foi significantemente superior. O mesmo ocorreu para o índice de Cobertura das despesas financeiras, quando as companhias participantes do ISE do setor Utilidade pública novamente se revelaram significantemente superiores às não participantes.

Tabela 4 - Resultado dos testes de diferenças entre médias de índices de gestão do capital de giro

\begin{tabular}{l|l|l|l|l|l|l|l|l}
\hline \multirow{2}{*}{ Índice } & \multicolumn{4}{l}{ 2.1. Margem EBITDA } & \multicolumn{3}{l}{ 2.2. Cobertura de despesas financeiras } \\
\cline { 2 - 10 } & \multicolumn{2}{l}{ Média } & & Sig. & \multicolumn{2}{l}{ Média } & & Sig. \\
\cline { 2 - 10 } & ISE & Não ISE & $z$ & (P-value) & ISE & Não ISE & $z$ & (P-value) \\
\hline Bens industriais & 0,14 & 1,18 & $-0,45$ & 0,65 & 4,78 & 1,56 & $-1,34$ & 0,18 \\
\hline Materiais básicos & 0,42 & 0,17 & $-2,02$ & $* 0,04$ & 5,90 & 5,55 & $-0,68$ & 0,50 \\
\hline Telecomunicação & 0,34 & 1,13 & $-0,45$ & 0,65 & 5,20 & 8,35 & $-1,34$ & 0,18 \\
\hline Utilidade pública & 1,40 & 0,27 & $-1,43$ & 0,15 & 5,21 & 2,80 & $-2,13$ & ${ }^{*} 0,03$ \\
\hline
\end{tabular}

*Diferença estatisticamente significante

Fonte: Elaborado pelo autor. 
Na análise dos índices de Liquidez (tabela 5), não foram observadas diferenças significantes entre os dois grupos de empresas.

Tabela 5 - Resultado dos testes de diferenças entre médias de índices de Liquidez

\begin{tabular}{|c|c|c|c|c|c|c|c|c|}
\hline \multirow{3}{*}{ Índice } & \multicolumn{4}{|c|}{ 3.1. Liquidez corrente } & \multicolumn{4}{|c|}{ 3.2. Liquidez seca } \\
\hline & \multicolumn{2}{|c|}{ Média } & \multirow[b]{2}{*}{$z$} & \multirow{2}{*}{$\begin{array}{l}\text { Sig. } \\
\text { (P-value) }\end{array}$} & \multicolumn{2}{|c|}{ Média } & \multirow[b]{2}{*}{ Z } & \multirow{2}{*}{$\begin{array}{l}\text { Sig. } \\
\text { (P-value }\end{array}$} \\
\hline & ISE & Não ISE & & & ISE & Não ISE & & \\
\hline Bens industriais & 1,81 & 0,32 & $-1,34$ & 0,18 & 1,10 & 0,24 & $-1,34$ & 0,18 \\
\hline Materiais básicos & 1,68 & 2,68 & $-1,69$ & 0,09 & 1,40 & 2,10 & $-1,52$ & 0,13 \\
\hline Telecomunicação & 1,02 & 0,84 & $-0,45$ & 0,65 & 1,00 & 0,83 & $-0,44$ & 0,65 \\
\hline Utilidade pública & 1,21 & 1,07 & $-1,08$ & 0,28 & 1,19 & 1,06 & $-0,94$ & 0,35 \\
\hline
\end{tabular}

Fonte: Elaborado pelo autor.

$\mathrm{Na}$ análise dos índices de Margem de lucratividade (tabela 6), também não foram observadas diferenças significantes entre companhias participantes e não participantes do ISE.

Tabela 6 - Resultado dos testes de diferenças entre médias de índices de Margem de Lucratividade

\begin{tabular}{|c|c|c|c|c|c|c|c|c|}
\hline \multirow[b]{3}{*}{ Índice } & \multicolumn{4}{|c|}{ 4.1. Rentabilidade do ativo } & \multicolumn{4}{|c|}{$\begin{array}{l}\text { 4.2. Rentabilidade do patrimônio } \\
\text { líquido }\end{array}$} \\
\hline & \multicolumn{2}{|c|}{ Média } & \multirow[b]{2}{*}{ z } & \multirow{2}{*}{$\begin{array}{l}\text { Sig. } \\
\text { (P-value) }\end{array}$} & \multicolumn{2}{|c|}{ Média } & \multirow[b]{2}{*}{$z$} & \multirow{2}{*}{$\begin{array}{l}\text { Sig. } \\
\text { (P-value) }\end{array}$} \\
\hline & ISE & $\begin{array}{l}\text { Não } \\
\text { ISE }\end{array}$ & & & ISE & Não ISE & & \\
\hline Bens industriais & 0,04 & $-0,01$ & $-0,45$ & 0,65 & 0,11 & 0,16 & $-0,45$ & 0,65 \\
\hline Materiais básicos & 0,08 & 0,04 & $-1,35$ & 0,18 & 0,13 & 0,07 & $-1,52$ & 0,13 \\
\hline Telecomunicação & 0,08 & 0,11 & $-1,34$ & 0,18 & 0,17 & 0,18 & $-0,45$ & 0,65 \\
\hline Utilidade pública & 0,08 & 0,05 & $-0,94$ & 0,35 & 0,18 & 0,23 & $-0,31$ & 0,75 \\
\hline
\end{tabular}

Fonte: Elaborado pelo autor.

Novamente, os índices de Rentabilidade sobre o investimento (tabela 7) não revelaram diferenças significantes entre as empresas reconhecidamente sustentáveis ou não. 
Tabela 7 - Resultado dos testes de diferenças entre médias de índices de Rentabilidade sobre o investimento

\begin{tabular}{|c|c|c|c|c|c|c|c|c|c|c|c|c|}
\hline \multirow{3}{*}{ Índice } & \multicolumn{4}{|c|}{ 5.1. Margem bruta } & \multicolumn{4}{|c|}{ 5.2. Margem operacional } & \multicolumn{4}{|c|}{ 5.3. Margem líquida } \\
\hline & \multicolumn{2}{|c|}{ Média } & \multirow[b]{2}{*}{ z } & \multirow{2}{*}{$\frac{\text { Sig. }}{\text { (P-value) }}$} & \multicolumn{2}{|c|}{ Média } & \multirow[b]{2}{*}{ z } & \multirow{2}{*}{$\frac{\text { Sig. }}{\text { (P-value) }}$} & \multicolumn{2}{|c|}{ Média } & \multirow[b]{2}{*}{ Z } & \multirow{2}{*}{$\frac{\text { Sig. }}{\text { (P-value) }}$} \\
\hline & ISE & $\begin{array}{l}\text { Não } \\
\text { ISE }\end{array}$ & & & ISE & $\begin{array}{l}\text { Não } \\
\text { ISE }\end{array}$ & & & ISE & $\begin{array}{l}\text { Não } \\
\text { ISE }\end{array}$ & & \\
\hline $\begin{array}{l}\text { Bens } \\
\text { industriais }\end{array}$ & 0,27 & 0,08 & $-1,34$ & 0,18 & 0,10 & 0,17 & $-0,45$ & 0,65 & 0,09 & 0,14 & $-0,45$ & 0,65 \\
\hline $\begin{array}{l}\text { Materiais } \\
\text { básicos }\end{array}$ & 0,23 & 0,36 & $-1,18$ & 0,24 & 0,21 & 0,13 & $-0,34$ & 0,74 & 0,17 & 0,09 & $-0,51$ & 0,61 \\
\hline $\begin{array}{l}\text { Telecom } \\
\text { unicação }\end{array}$ & 0,46 & 0,54 & $-1,34$ & 0,18 & 0,19 & 1,04 & $-0,45$ & 0,65 & 0,15 & 0,92 & $-1,34$ & 0,18 \\
\hline $\begin{array}{l}\text { Utilidade } \\
\text { pública }\end{array}$ & 0,43 & 0,42 & $-1,17$ & 0,86 & 0,29 & 0,20 & $-1,15$ & 0,25 & 0,21 & $-0,01$ & $-1,22$ & 0,22 \\
\hline
\end{tabular}

Fonte: Elaborado pelo autor.

Por último, a análise dos índices de Valor de mercado (tabela 8) também não revelou diferenças significantes entre os dois grupos de empresas.

Tabela 8 - Resultado dos testes de diferenças entre médias de índices de Valor de Mercado

\begin{tabular}{|c|c|c|c|c|c|c|c|c|}
\hline \multirow[b]{3}{*}{ Índice } & \multicolumn{4}{|c|}{ 6.1. Preço/Valor patrimonial da ação } & \multicolumn{4}{|c|}{ 6.2. Preço/Lucro } \\
\hline & \multicolumn{2}{|c|}{ Média } & \multirow[b]{2}{*}{$z$} & \multirow{2}{*}{$\begin{array}{l}\text { Sig. } \\
\text { (P-value) }\end{array}$} & \multicolumn{2}{|l|}{ Média } & \multirow[b]{2}{*}{$\mathrm{z}$} & \multirow{2}{*}{$\begin{array}{l}\text { Sig. } \\
\text { (P-value) }\end{array}$} \\
\hline & ISE & $\begin{array}{l}\text { Não } \\
\text { ISE }\end{array}$ & & & ISE & Não ISE & & \\
\hline Bens industriais & 1,62 & 1,03 & $-0,45$ & 0,65 & 15,41 & 2,31 & $-1,34$ & 0,18 \\
\hline Materiais básicos & 1,36 & 1,07 & $-1,01$ & 0,31 & 11,90 & 18,33 & $-0,17$ & 0,87 \\
\hline $\begin{array}{l}\text { Telecomu } \\
\text { nicação }\end{array}$ & 0,49 & 1,91 & $-1,34$ & 0,18 & 3,07 & 10,31 & $-0,45$ & 0,65 \\
\hline Utilidade pública & 1,97 & 1,15 & $-0,45$ & 0,65 & 15,49 & 32,60 & $-0,52$ & 0,60 \\
\hline
\end{tabular}

Fonte: Elaborado pelo autor.

\subsection{Discussão dos resultados}

$\mathrm{Na}$ análise geral dos indicadores financeiros de empresas participantes e não participantes do ISE, este estudo revelou não haver diferença significante entre os indicadores financeiros dos dois 
grupos, indicando, assim, semelhança no desempenho das empresas. Esses resultados corroboram com os achados de Macedo et al. (2007), Rezende, Nunes e Portela (2008), Machado, Machado e Corrar (2009), Gomes e Torquato (2011), Macedo, Corrar e Siqueira (2012), Todeschini e Mello (2011), que, em uma análise geral sem diferenciação por setor econômico, também não identificaram diferença significante no desempenho financeiro de empresas reconhecidamente sustentáveis ou não.

Por outro lado, a análise por setor econômico revelou haver diferenças significantes no setor de Materiais másicos, em que o índice margem EBITDA das empresas participantes foi significantemente superior às empresas não participantes do ISE, e no setor de Utilidade pública, em que o índice Cobertura das despesas financeiras das empresas participantes também revelou desempenho significantemente superior. Por sua vez, estes achados estão em consonância com os achados de Teixeira, Nossa e Funchal (2011), Macedo, Corrar e Siqueira (2012), Mazzioniet al. (2013) e Barakat et al. (2016), uma vez que também identificaram superioridade no desempenho financeiro de empresas participantes do ISE.

No setor de Utilidade pública, a superioridade do índice Cobertura das despesas financeiras das empresas participantes do ISE se assemelha com os achados de Teixeira, Nossa e Funchal (2011) de Todeschini e Mello (2011), que também encontraram relação negativa com o endividamento de empresas sustentáveis. Todeschini e Mello (2011), embora não tenham encontrado diferença significante na análise geral, encontraram desempenho financeiro significante superior pelas empresas participantes do ISE quando analisaram por setor econômico. Esses autores também encontraram desempenho significantemente superior nos setores de Consumo não cíclico/Saúde e Financeiros e outros/Intermediários financeiros nas empresas participantes do ISE.

Situação semelhante foi constatada pelos achados de Macedo, Corrar e Siqueira (2012), uma vez que, em uma análise geral, não encontraram desempenho financeiro significantemente superior para 
as empresas participantes do ISE. Por outro lado, na análise por setor econômico, os indicadores de Liquidez corrente e Endividamento no curto prazo nos setores de Papel e celulose, e o indicador de Endividamento no curto prazo no setor de Química e Petroquímica, das empresas participantes do ISE foram significantemente superiores às empresas não participantes. Já a superioridade dos índices margem EBITDA e Cobertura das despesas financeiras pelas empresas participantes do ISE, revelada neste estudo, mostra-se contrária aos achados de Vital el. (2009), que encontrou superioridade nestes dois indicadores para empresas que não faziam parte do ISE.

\section{Conclusão}

Este estudo teve como objetivo principal avaliar o desempenho financeiro de empresas participantes do ISE da BM\&FBovespa, que reconhecidamente incorporam princípios de sustentabilidade, em comparação às empresas não participantes, exceto instituições financeiras. Em um contexto em que as empresas sustentáveis têm atraído a atenção de investidores, desejou-se analisar o retorno financeiro dessas empresas. Foi utilizada uma amostra de 28 empresas participantes e 28 empresas não participantes do ISE em 31 de março de 2014. Desta forma, foram coletadas informações financeiras referentes ao período de 31 de dezembro de 2013.

Os resultados revelaram não haver diferença significante no desempenho financeiro das empresas participantes e não participantes do ISE, corroborando com os resultados encontrados por de Macedo et al. (2007), Rezende, Nunes e Portela (2008), Machado, Machado e Corrar (2009), Gomes e Torquato (2011), Macedo, Corrar e Siqueira (2012), Todeschini e Mello (2011). Por outro lado, quando analisados por setor econômico, foram reveladas diferenças significantes no setor econômico Materiais básicos, no índice margem EBITDA, e no setor econômico Utilidade pública, no índice Cobertura das despesas financeiras. Em ambos os casos, os indicadores das empresas participantes do ISE revelaram-se significantemente superiores às 
empresas não participantes do ISE. Estes achados corroboram com aqueles encontrados por Teixeira, Nossa e Funchal (2011), Teixeira, Nossa e Funchal (2011), e Mazzioni et al. (2013), assim como com os resultados por setor econômico de Todeschini e Mello (2011) Macedo, Corrar e Siqueira (2012), e Barakat et al. (2016). Porém, estão em desacordo com os resultados de Vital el. (2009).

Merece destaque que, mesmo tendo encontrado desempenho financeiro superior pelas empresas participantes do ISE em apenas nas duas ocasiões descritas acima, não foi revelada nenhuma ocasião de superioridade dos índices pelas empresas não participantes do ISE. Desta forma, pode-se concluir que não há evidências de que os custos adicionais decorrentes de ações de sustentabilidade de empresas participantes do ISE impactassem negativamente em seu desempenho financeiro.

Este trabalho se apresenta como uma iniciativa de discussão do tema da sustentabildade de forma direta, por meio de uma comparação direta e objetiva, utilizando o desempenho financeiro como base de comparação. Porém, apresenta limitações, como a pequena quantidade de empresas que foram analisadas. Além disso, não foi possível analisar os setores Consumo não básico, Consumo cíclico, Consumo não cíclico e Construção e transporte, uma vez que os resultados dos testes estatísticos de Wilcoxon foram omissos ("missingvalues"). Para as futuras pesquisas, sugerem-se estudos com combinação de técnicas estatísticas mais sofisticadas, como a análise de dados em painel, com mais setores e incluindo algumas variáveis de controle.

\section{Referências}

BARAKAT, S. R.; SANCHES, M. V.; MACLENNAN, M. L. F.; POLO, E.; OLIVEIRA JÚNIOR, M. M. Associação entre Desempenho Econômico e Índice de Sustentabilidade Empresarial da Bolsa de Valores de São Paulo. Gestão \& Regionalidade, São Paulo, v. 32, n. 95, p. 127-142, maio-ago. 2016. 
BARBIERI, J. C.; CAJAZEIRA, J. E. R. Responsabilidade social empresarial e empresa sustentável. São Paulo: Saraiva, 2009.

BM\&FBOVESPA. Índice de Sustentabilidade Empresarial - ISE.

Disponível em: <http://www.bmfbovespa.com.br/Indices/download/ISE. pdf>. Acesso em: 05 abril 2014.

GALLON, A. V.; ENSSLIN, S. R. Evidenciação estratégica dos pilares da sustentabilidade empresarial: investigação no Relatório da Administração das empresas que compõem o ISE.

Revista Pensar Contábil, Rio de Janeiro, v. 1, n.1, p. 5-14, jul./set. 2008.

GOMES, F. P.; TORTATO, U. Adoção de práticas de sustentabilidade como vantagem competitiva: evidências empíricas. Revista

Pensamento Contemporâneo em Administração, Rio de Janeiro, v. 5, n. 2, p. 33-49, maio/ago 2011.

KNOEPFEL, I. Dow Jones sustainability group index: a global benchmark for corporate sustainability. Corporate Environmental Strategy, [S.I], v. 8, n. 1, p. 6-15, Apr. 2001.

MACEDO, M. A. S.; CORRAR, L. J.; SIQUEIRA, J. R. M. Análise comparativa do desempenho contábil-financeiro de empresas socioambientalmente responsáveis no Brasil. BASE - Revista de Administração e Contabilidade da UNISINOS, São Leopoldo/RS, v. 9, n. 1, p. 13-26, jan./mar. 2012.

MACEDO, M. A. S.; SOUSA, A. C.; SOUSA, A. C. C.; CÍPOLA, F. C. Análise comparativa do desempenho contábil-financeiro de empresas socialmente responsáveis. Pensar Contábil, Rio de Janeiro, v. 11, n. 43, art. 2, p. 15-23, jan./mar. 2009.

MACHADO, M.R.; MACHADO, M.A.V.; CORRAR, L.J. Desempenho do índice de sustentabilidade empresarial (ISE) da bolsa de valores de São Paulo. Revista Universo Contábil (Online), Blumenau, v. 5, n. 2, p. 24-38, 2009. 
MARREWIJK, M. V.; TIMMERS, J. Human capital management: new possibilities in people management. Journal of Business Ethics, Netherlands, v. 44, n. 2-3, p. 171-184, Maio 2003.

MARTINS, G. A. Manual para elaboração de monografias e dissertações. 2. ed. São Paulo: Atlas, 1994.

MAY, P.; LUSTOSA, M.C.; VINHA, V. Economia do meio ambiente: teoria e prática. Rio de Janeiro: Campus, 2003.

MAZZIONI, S.; DIEL, F. J.; DIEL, E. H.; KRUGER, S. D.; KLANN, R. C. Análise dos Indicadores de valor adicionado das empresas participantes do Índice de Sustentabilidade Empresarial (ISE) e das demais empresas listadas na BM\& F Bovespa. Contextus - Revista Contemporânea de Economia e Gestão, Fortaleza, v. 11, n. 2, p. 159-180, jul./dez. 2013.

NUNES, J. G.; PORTELA, S. S.; TEIXEIRA, A. J.; SILVA, A. R. L. Análise das variáveis que influenciam a adesão das empresas ao índice BM\&F Bovespa de sustentabilidade empresarial. BASE Revista de Administração e Contabilidade da UNISINOS. São Leopoldo/RS, v.7 n. 4, p. 328-340, out/dez.. 2010.

PLETSCH, C. S.; SILVA, A.; HEIN, N. Responsabilidade social e desempenho econômico-financeiro das empresas listadas no Índice de Sustentabilidade Empresarial - ISE. RGSA - Revista de Gestão Social e Ambiental, São Paulo, v. 9, n. 2, p. 53-69, maio/ago. 2015.

REZENDE, I. A. C.; NUNES, J. G.; PORTELA, S. S.. Um estudo sobre o desempenho financeiro do índice bovespa de sustentabilidade empresarial. Revista de Educação e Pesquisa em Contabilidade, Brasília, v. 2, n. 1, p. 71-93, jan/abr. 2008.

STRONG, M. Prefácio. In: SACHS, I. Estratégias de transição para o século XXI: desenvolvimento e meio ambiente. São Paulo: Studio Nobel/FUNDAP, 1993, p. 7-9.

TEIXEIRA, E. A.; NOSSA, V; FUNCHAL, B. O índice de sustentabilidade empresarial (ISE) e os impactos no endividamento 
e na percepção de risco. Revista Contabilidade \& Finanças - USP, São Paulo v. 22, n. 55, p. 29-44, jan./fev./mar./abr. 2011.

TODESCHINI, C.; MELLO, G. R. Evidências empíricas sobre desempenho e sustentabilidade empresarial. In:CONGRESSO USP DE INICIAÇÃO CIENTÍFICA EM CONTABILIDADE, 8., 2011, São Paulo. Anais... São Paulo: USP, p. 1-14, 2011.

VITAL, J. T.; CAVALCANTI, M. M.; DALLÓ, S.; MORITZ, G. O.; COSTA, A. M. A influência da participação no Índice de Sustentabilidade Empresarial (ISE) Desempenho Financeiro das Empresas. Revista de Ciências da Administração, Florianópolis/SC, v.11, n.24, p. 11-40, maio/ago. 2009.

Data de Submissão: 26/02/16

Data de Aprovação: 12/08/16 